\title{
Sag niemals nie ...
}

\section{Tanja Kühnle}

Dipl.-Biol., Managing Editor

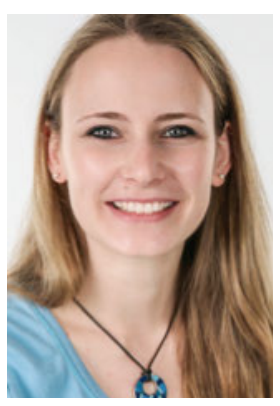

Kurz nach meiner Geburt hat sich meine Mama dazu entschieden, ihren Job aufzugeben. Auch als meine kleine Schwester und ich älter wurden, ist sie nicht wieder in den Beruf eingestiegen. Die Arbeitsteilung zu Hause war deshalb klar: Meine Mama hat sich um uns Kinder und den Haushalt gekümmert, mein Papa hat das Geld verdient. In unserem Familien- und Freundeskreis war das meist ähnlich. Und so manche Frau in unserem Umfeld, die trotz Kindern wieder arbeiten ging, wurde insgeheim mit einem Kopfschütteln bedacht.

Auch ich war lange der festen Überzeugung, dass ich meinen Beruf aufgeben würde, falls ich einmal das Glück haben sollte, Mama zu werden. Ich konnte mir einfach nicht vorstellen, mein Kind in eine Kindertagesstätte (KiTa) zu geben und dort von irgendwelchen mir unbekannten Menschen betreuen zu lassen. Ich fand das verantwortungslos. Und ich wollte mein Kind, insbesondere in den ersten Lebensjahren, selbst erziehen, ihm meine eigenen Wertevorstellungen nahebringen.

Heute bin ich Mama eines zweijährigen Jungen und habe wie mein Mann eine 100\%-Stelle, so dass unser Kind Vollzeit in eine KiTa geht. Und mit dieser Situation sind wir - ich denke, da spreche ich für uns drei sehr glücklich. Jetzt fragen Sie vielleicht: Wie ist es dazu gekommen? Nun ...

\section{Ich konnte mir einfach nicht vorstellen, mein Kind in eine KiTa zu geben.}

Spätestens seit meinem Einstieg ins Berufsleben war mir klar, dass ich einmal trotz Familie wieder schnell würde in meinen Job einsteigen wollen, denn ich mag meine Arbeit sehr. Es macht mir Freude, eine Zeitschrift zu gestalten und eigene Texte zu schreiben. Ich bin gern unter Kollegen. Und ich möchte - auch wenn mein Mann gut für unsere Familie sorgt - finanziell auf eigenen Beinen stehen können. Schliesslich kann man nie wissen, was im Leben passiert. Und ich finde es wichtig, ausreichend Geld fürs Alter zurückzulegen. Denn meiner Meinung nach ist es primär meine Aufgabe, Vorkehrungen zu treffen, damit ich später einmal finanziell gut versorgt bin - nicht die meines Kindes oder die des Staates.
Und was ist aus der Ansicht geworden, dass ich mein Kind lieber selbst erziehen will? Einige meiner Freundinnen sind deutlich vor mir Mama geworden. Fast alle sind nach kurzer Zeit wieder in ihren Beruf eingestiegen. Sie haben mir davon erzählt, wie gut es ihren Kindern in der KiTa gefällt. Und dass die Kleinen viel voneinander lernen, was ihnen ein Erwachsener wahrscheinlich gar nicht so gut zeigen kann. Ausserdem habe ich oft gehört, dass es meine Freundinnen geniessen, während der Arbeit ein wenig Auszeit vom "Mamasein» zu haben. Dass es ihnen guttut, mal nicht auf den Nachwuchs achten zu müssen. Und dass sie sich dann abends umso mehr auf die gemeinsame Zeit in der Familie freuen.

\section{Aber seit ich nicht mehr «nur» auf meinen Sohn aufpasse, bin ich viel glücklicher.}

Das ist auch meine Erfahrung. Ich finde es wunderschön, Mama zu sein. Aber seit ich nicht mehr «nur» auf meinen Sohn aufpasse und versuche, ihm einen schönen Tag und den Haushalt zu machen, bin ich viel glücklicher. Und vor allem ausgeglichener. Zugegeben: Manchmal, wenn ich auf der Arbeit bin, denke ich mit ein bisschen Wehmut darüber nach, was mein Kleiner in der KiTa gerade wohl macht. Und hin und wieder frage ich mich, ob ich vielleicht in diesem Moment einen wichtigen Schritt in seiner Entwicklung verpasse. Aber ich weiss, dass er in der KiTa gut versorgt ist. Dass es ihm gut gefällt, dass seine Freunde dort sind und dass er an Freizeitaktivitäten einiges geboten bekommt, was ich ihm allein nicht oder nur unter grossen Anstrengungen bieten könnte. So war ich bislang noch nie "mutig» genug, ein Planschbecken im Wohnzimmer aufzustellen, um auf dem Wasser Entchen und Schiffchen fahren zu lassen. Aber wer weiss, vielleicht werde ich das mal auf einem Kindergeburtstag ausprobieren. Schliesslich soll man niemals nie sagen ...

P.S. Ich habe grössten Respekt vor allen Mamas und Papas, die sich dafür entschieden haben, bei ihren Kindern zu Hause zu bleiben. Und ich freue mich für jeden, der darin seine Aufgabe gefunden hat. Nur habe ich für mich festgestellt, dass es nicht meine Erfüllung ist. 